\title{
Componentes externos e gordura interna de novilhos Charolês ou Nelore alimentados com diferentes proporções de concentrado
}

\section{External body components and internal fat of Charolais or Nellore steers, fed with different concentrate level}

\author{
Magali Floriano da Silveira' ${ }^{*}$; Dari Celestino Alves Filho²; Regis Luis Missio \\ Patrícia Alessandra Meneguzzi Metz; ${ }^{4}$ João Restle ${ }^{5}$ Luciane Rumpel Segabinazzi ${ }^{6}$; \\ Álisson Marian Callegaro; ${ }^{6}$ Guilherme Joner ${ }^{7}$
}

\begin{abstract}
Resumo
Avaliaram-se os componentes externos e a distribuição da gordura interna de novilhos das raças Charolês $(\mathrm{CH})$ ou Nelore (NE), alimentados com diferentes proporções de concentrado na dieta. Os novilhos foram distribuídos em seis tratamentos que corresponderam a três níveis de concentrado: 35 , 50 e $65 \%$ (com base na matéria seca) e dois grupos genéticos (Charolês e Nelore). Os novilhos NE alimentados com $65 \%$ de concentrado na dieta apresentaram maior rendimento de corpo vazio (RCV), não diferindo dos novilhos $\mathrm{CH}$ e $\mathrm{NE}$ alimentados com $50 \%$ de concentrado. $\mathrm{O}$ peso da cabeça ajustado para peso de corpo vazio (PCV) foi menor para os animais que consumiram dieta com proporção mais alta de concentrado $(4,67,4,30$ e 4,28 para 35,50 e $65 \%$ de concentrado, respectivamente) e para os novilhos da raça $\mathrm{NE}$ em relação aos $\mathrm{CH}$ (4,30 contra 4,54, respectivamente). O peso absoluto total das gorduras internas foi superior $(\mathrm{P}<0,05)$ para os novilhos alimentados com proporções mais elevadas de concentrado $(18,13 ; 22,58$ e $21,74 \mathrm{~kg}$ para 3550 e $65 \%$ de concentrado), e para os novilhos $\mathrm{CH}$ em relação aos NE (22,52 contra 19,11, respectivamente). Novilhos $\mathrm{CH}$ apresentam maior deposição de gordura interna do que novilhos NE. Novilhos alimentados com proporções mais altas de concentrado apresentam maiores deposições de gordura interna.
\end{abstract}

Palavras-chave: Cabeça, couro, gordura renal, peso de corpo vazio

\begin{abstract}
The objective was to evaluate the development of external body components and the distribution of internal fat of Charolais (CH) and Nellore (NE) steers, fed with different concentrate level in the diet. The steers were distributed in six treatments constituted by three concentrate level: 35,50 or $65 \%$ (dry matter basis) and two genetic group (Charolais or Nellore). NE steers fed with $65 \%$ concentrate in diet showed higher EBW yield, it was not different to $\mathrm{CH}$ and NE steers fed with $50 \%$ concentrate. Head weigth in relation to EBW was decrease with the increase of the proportions concentrate $(4.67,4.30$ and
\end{abstract}

\footnotetext{
${ }^{1}$ Zootecnista, Dept $^{0}$ de Zootecnia, Universidade Federal de Santa Maria, UFSM, Av. Roraima, 1000, Camobi, 97105-900. Santa Maria, RS. E-mail: mg flor@yahoo.com.br

${ }^{2}$ Eng $^{\circ}$ Agr $^{\circ}$, Prof. do Dept ${ }^{\circ}$ de Zootecnia, UFSM, Santa Maria, RS. E-mail:darialvesfilho@hotmail.com

${ }^{3}$ Zootecnista, Discente de Pós-Doutorado da Universidade Federal de Góias, UFG, Goiânia, GO. E-mail: regisluismissio@hotmail. com

${ }^{4}$ Zootecnista, Prof ${ }^{a}$. Colégio Agrícola de Frederico Westphalen,UFSM, Frederico Westphlen, RS. E-mail:patimetz@hotmail.com

${ }^{5}$ Eng $^{\circ}$ Agr ${ }^{\circ}$, Prof. Visitante, UFG, Goiânia, GO. E-mail: jorestle@terra.com.br

${ }^{6}$ Zootecnista(s), M.e. Discente(s) de Doutorado, UFSM, Santa Maria, RS. E-mail: luzoot@hotmail.com; mcalisson@yahoo.com. br

${ }^{7}$ Discente de Zootecnia da UFSM, Santa Maria, RS. E-mail:jonerzootecnista@yahoo.com.br

* Autor para correspondência
} 
4.28 to $35 ; 50$ and $65 \%$ concentrate, respectively). The head weigh also was lower from NE steers in relation to $\mathrm{CH}$ steers ( 4.30 versus 4.54 , respectively). The absolute total weight of internal fat was higher $(\mathrm{P}<.05)$ for steers fed with high concentrate proportions $(18.13 ; 22.58$ and $21.74 \mathrm{~kg}$ to 35,50 and $65 \%$ concentrate) and to $\mathrm{CH}$ steers in relation to NE (22.52 versus 19.11, respectively). CH steers showed highest internal fat. Similarly, steers fed high-concentrate ratio had also higher deposit of internal fat.

Key words: Head, hide, renal fat, empty body weight

\section{Introdução}

A avaliação quantitativa dos componentes nãointegrantes da carcaça é de suma importância, pois afetam o rendimento de carcaça e as exigências nutricionais dos bovinos. Atualmente, contribuem para aumentar a receita dos frigoríficos, principalmente, pela comercialização do couro e de resíduos utilizados na indústria de rações. Essas características variam de acordo com a raça, regime alimentar e estádio de maturidade (VELOSO et al., 2002). Alguns pesquisadores observaram que animais zebuínos apresentam o peso dos componentes externos superior aos animais europeus e mestiços-europeus (PACHECO et al., 2005a; BACKES et al., 2006). Segundo Pacheco et al. (2005b) e Menezes et al. (2005), animais com predominância de sangue Nelore apresentam maiores valores para comprimento de carcaça, perna e braço, como resultado da maior adaptabilidade das raças zebuínas a climas quentes, resultando em maior peso dos componentes externos.

O local de deposição de gordura parece afetar as exigências de energia de mantença. Thompson et al. (1983) observaram maior atividade metabólica do tecido adiposo interno do que no tecido adiposo subcutâneo. A deposição de tecido adiposo ocorre seguindo uma escala decrescente sugerida por Di Marco (1998): intermuscular, subcutânea, interna, visceral e intramuscular. Perón et al. (1993) relataram que animais mestiços holandeses apresentam maior proporção de gordura interna do que animais de raças de corte. Além disso, segundo Menezes et al. (2009), o excesso nos depósitos de gordura corporal diminui a eficiência alimentar e afeta a lucratividade do produtor, pois o excesso de gordura é removido da carcaça antes da sua pesagem, não havendo remuneração.
Animais da raça NE depositam mais precocemente gordura subcutânea do que animais da raça CH (RESTLE et al., 2000, 2002; MENEZES et al., 2005) e estes por sua vez, parecem depositar maior quantidade de gordura interna do que os NE (MENEZES et al., 2009). Para acabamento mais precoce nos animais $\mathrm{CH}$, há necessidade de fornecimento de dietas com alta densidade energética.

O objetivo deste estudo foi avaliar a influencia de diferentes níveis de concentrado na dieta de novilhos Charolês ou Nelore terminados em confinamento sobre os componentes externos e a distribuição das gorduras internas e de descarte.

\section{Material e Métodos}

O estudo foi conduzido no Laboratório de Bovinocultura de Corte, do Departamento de Zootecnia da Universidade Federal de Santa Maria. Foram utilizados 22 novilhos castrados, sendo 11 da raça Charolês e 11 da raça Nelore. Os animais no início do experimento apresentavam média de idade de 22 meses e peso médio de $195 \mathrm{~kg}$, oriundos do mesmo rebanho experimental. Os novilhos foram distribuídos em seis tratamentos que corresponderam a três níveis de concentrado: 35, 50 e 65\% (com base na matéria seca) e dois grupos genéticos (Charolês e Nelore). No tratamento com $35 \%$ de concentrado, usaram-se oito animais (quatro de cada grupo genético) e nos demais, sete (quatro Charolês e três Nelore). Os novilhos foram alimentados ad libitum, duas vezes ao dia, sendo uma pela manhã $(8 \mathrm{~h})$ e outra à tarde (16 h), ajustando sobra diária em torno de $10 \%$ do oferecido. A dieta foi calculada para ganho de 1,4 kg/animal/dia, contendo $13 \%$ de proteína bruta $(\mathrm{PB})$. A fração concentrada foi 
composta por grão de milho triturado, farelo de trigo, farelo de soja, ureia, calcário calcítico, cloreto de sódio e monensina sódica (Tabela 1). O volumoso foi composto pelas silagens de milho e sorgo em partes iguais. Os animais foram abatidos quando atingiram acabamento mínimo $(3 \mathrm{~mm})$ desejado pelos frigoríficos da região.

Tabela 1. Composição percentual dos ingredientes conforme o tratamento alimentar.

\begin{tabular}{lccc}
\hline \multirow{2}{*}{ Ingredientes } & \multicolumn{3}{c}{ Nível de concentrado (\%) } \\
\cline { 2 - 4 } & 35 & 50 & 65 \\
\hline Grão de milho \% & 8,56 & 6,00 & 5,40 \\
Farelo de trigo \% & 74,6 & 85,00 & 88,96 \\
Farelo de soja \% & 8,56 & 4,00 & 1,06 \\
Uréia \% & 1,96 & 0,60 & 0,00 \\
Calcário calcítico \% & 3,4 & 2,36 & 3,03 \\
Sal comum \% & 2,8 & 1,96 & 1,53 \\
Rumensin, g/100kgde conc. & 44 & 33 & 25,6 \\
\hline
\end{tabular}

Fonte: Elaboração dos autores.

Após 138 dias de confinamento, os novilhos permaneceram em jejum total de $14 \mathrm{~h}$, e em seguida foram conduzidos em caminhão boiadeiro por 25 $\mathrm{km}$ para frigorífico comercial, onde o abate ocorreu no momento do desembarque. $\mathrm{O}$ abate seguiu $\mathrm{o}$ fluxo normal do estabelecimento, sendo que o peso final obtido na fazenda foi considerado como peso de abate.

No momento do abate foram tomados os pesos de cabeça, patas, sangue, couro, vassoura da cauda (componentes externos), retículo-rúmen, omaso, abomaso, intestino delgado, intestino grosso (trato gastrintestinal), coração, rins, fígado, pulmão (órgãos vitais) e gordura das vísceras (inguinal, renal, ruminal, intestinal, do abomaso, coração) (gordura interna) e gordura de toalete. O somatório das gorduras internas e gordura de toalete representaram à gordura total descartada. Para a obtenção do peso corporal vazio (PCV) utilizou-se a soma dos pesos de carcaça quente, sangue, componentes externos, órgãos vitais, trato gastrintestinal vazio e a gordura total.

O delineamento experimental utilizado foi $\mathrm{o}$ inteiramente ao acaso, em esquema fatorial $3 \times 2$ (três níveis de concentrado $\mathrm{x}$ duas raças). Os dados foram submetidos à análise de variância e teste $\mathrm{F}$.
As médias foram comparadas pelo procedimento pdiff (teste "t") utilizando programa estatístico SAS (2001).

\section{Resultados e Discussão}

Houve interação significativa entre nível de concentrado e raça para rendimento de corpo vazio (RCV) e conteúdo do trato gastrintestinal (CTGI) (Tabela 2). Novilhos NE apresentaram maior RCV quando alimentados com $65 \%$ de concentrado na dieta, não diferindo dos novilhos $\mathrm{CH}$ e $\mathrm{NE}$ alimentados com $50 \%$ de concentrado. Este maior RCV pode ser explicado pelo menor conteúdo do trato gastrintestinal (CTGI), apresentado pelos novilhos NE, haja vista o decréscimo do consumo de alimentos volumosos. $\mathrm{O}$ volume do trato digestivo dos ruminantes diminui em função do maior consumo de concentrado (GESUALDI JÚNIOR et al. 2001), devido ao maior aporte de nutrientes digestíveis totais, provocando menor enchimento e limitando o consumo (VAN SOEST, 1994). No presente estudo, a correlação entre RCV e CTGI foi negativa $(r=-0,62 ; \mathrm{P}=0,0022)$, concordando com Kuss et al. (2008) que encontraram correlação de $-0,88$ para estas variáveis. No estudo de Galvão et 
al. (1991), novilhos NE apresentaram rendimento de carcaça menor do que os novilhos mestiços europeu-zebu, e os pesquisadores atribuíram este fato às variações no peso do trato gastrintestinal (TGI). Menezes e Restle (2005) observaram menor tamanho do TGI em novilhos Nelore em comparação a novilhos Charolês, devido ao menor potencial de consumo dos primeiros, no entanto, não encontraram diferença para RCV entre estes dois genótipos.
$\mathrm{O}$ peso de abate dos novilhos Charolês $(\mathrm{CH})$ foi superior $(\mathrm{P}<0,01)$ ao dos novilhos Nelore $(\mathrm{NE})$ (Tabela 2). Esta diferença entre raças encontrase bem documentada na literatura (RESTLE et al., 2001; FATURI et al., 2002; MENEZES et al., 2005), que confirmam que a raça Charolês apresenta como principal característica, a alta velocidade de deposição muscular, propiciando alto peso ao abate (RESTLE et al., 2001).

Tabela 2. Médias e erros-padrão para características de peso de abate, peso de corpo vazio, rendimento de corpo vazio, conteúdo do trato gastrintestinal (CTGI) de novilhos Charolês $(\mathrm{CH})$ e Nelore (NE) alimentados com diferentes proporções de concentrado na dieta.

\begin{tabular}{|c|c|c|c|c|}
\hline \multirow{2}{*}{ Grupo genético } & \multicolumn{3}{|c|}{ Nível de concentrado (\%) } & \multirow{2}{*}{ Média } \\
\hline & 35 & 50 & 65 & \\
\hline \multicolumn{5}{|c|}{ Peso de abate, $\mathrm{kg}$} \\
\hline $\mathrm{CH}$ & $348,80 \pm 9,69$ & $374,67 \pm 12,51$ & $393,00 \pm 12,51$ & $372,15 \mathrm{~A}$ \\
\hline $\mathrm{NE}$ & $323,00 \pm 12,51$ & $332,00 \pm 10,84$ & $321,75 \pm 10,84$ & $325,58 \mathrm{~B}$ \\
\hline Média & 335,9 & 353,3 & 357,4 & \\
\hline \multicolumn{5}{|c|}{ Peso de corpo vazio, $\mathrm{kg}$} \\
\hline $\mathrm{CH}$ & $289,41 \pm 8,94$ & $319,64 \pm 11,54$ & $324,99 \pm 11,54$ & $311,34 \mathrm{~A}$ \\
\hline $\mathrm{NE}$ & $268,28 \pm 11,54$ & $280,91 \pm 10,00$ & $280,02 \pm 10,00$ & $276,40 \mathrm{~B}$ \\
\hline Média & $278,8 \mathrm{~b}$ & $300,3 \mathrm{ab}$ & $302,5 \mathrm{a}$ & \\
\hline \multicolumn{5}{|c|}{ Rendimento de corpo vazio, $\%$} \\
\hline $\mathrm{CH}$ & $82,97 \pm 0,81 \mathrm{~b}$ & $85,24 \pm 1,05 \mathrm{ab}$ & $82,71 \pm 1,05 b$ & 83,64 \\
\hline NE & $83,04 \pm 1,05 \mathrm{~b}$ & $84,61 \pm 0,91 \mathrm{ab}$ & $87,05 \pm 0,91 \mathrm{a}$ & 84,90 \\
\hline Média & 83,00 & 84,93 & 84,90 & \\
\hline \multicolumn{5}{|c|}{ Conteúdo Trato Gastrintestinal (CTGI), kg } \\
\hline $\mathrm{CH}$ & $56,70 \pm 2,54 \mathrm{a}$ & $53,17 \pm 3,28 \mathrm{ab}$ & $60,63 \pm 3,28 \mathrm{a}$ & 56,83 \\
\hline NE & $40,57 \pm 3,28 \mathrm{c}$ & $44,32 \pm 2,84 \mathrm{bc}$ & $39,10 \pm 2,84 \mathrm{c}$ & 41,33 \\
\hline Média & 48,63 & 48,74 & 49,87 & \\
\hline \multicolumn{5}{|c|}{ Conteúdo Trato Gastrintestinal (CTGI), \% PCV } \\
\hline $\mathrm{CH}$ & $19,65 \pm 0,92 \mathrm{a}$ & $16,79 \pm 1,18 \mathrm{ab}$ & $18,63 \pm 1,18 \mathrm{a}$ & 18,35 \\
\hline $\mathrm{NE}$ & $15,17 \pm 1,18 b$ & $15,79 \pm 1,03 b$ & $13,97 \pm 1,03 b$ & 14,98 \\
\hline Média & 17,41 & 16,29 & 16,30 & \\
\hline \multicolumn{5}{|c|}{ Conteúdo Trato Gastrintestinal (CTGI), \% PA } \\
\hline $\mathrm{CH}$ & $16,26 \pm 0,67 \mathrm{a}$ & $14,30 \pm 0,86 \mathrm{ab}$ & $15,39 \pm 0,86 \mathrm{a}$ & 15,32 \\
\hline $\mathrm{NE}$ & $12,59 \pm 0,86 b$ & $13,36 \pm 0,75 b$ & $12,12 \pm 0,75 b$ & 12,69 \\
\hline Média & 14,43 & 13,83 & 13,76 & \\
\hline
\end{tabular}

$\mathrm{A}, \mathrm{B}=$ médias seguidas por letras maiúsculas na coluna diferem $(\mathrm{P}<0,01)$ pelo teste $\mathrm{t}$.

$\mathrm{a}, \mathrm{b}=$ médias seguidas por letras minúsculas na linha e coluna diferem $(\mathrm{P}<0,05)$ pelo teste $\mathrm{t}$.

Fonte: Elaboração dos autores. 
$\mathrm{O}$ maior peso de abate dos novilhos $\mathrm{CH}$ proporcionou maior $(\mathrm{P}<0,05)$ peso de corpo vazio (PCV) em relação aos NE. Com o aumento da proporção de concentrado na dieta houve aumento $(\mathrm{P}<0,05)$ do $\mathrm{PCV}$, tal fato pode ter ocorrido pelos maiores pesos de abate proporcionado pelo aumento dos níveis de concentrado.
O peso absoluto da cabeça, patas, vassoura da cauda, couro e do conjunto dos componentes externos (CCE) não foram influenciados $(\mathrm{P}>0,05)$ pela proporção de concentrado na dieta (Tabela 3). No entanto, o peso da cabeça quando ajustado para $\%$ do corpo vazio (PCV) e \% peso de abate (PA) foi menor $(\mathrm{P}<0,05)$ para os novilhos que receberam proporção mais alta de concentrado.

Tabela 3. Médias e erros-padrão para características de cabeça, patas, vassoura da cauda, couro e o total dos componentes externos em peso absoluto, em percentagem do peso de corpo vazio e do peso de abate.

\begin{tabular}{|c|c|c|c|c|}
\hline \multirow{2}{*}{ Características } & \multicolumn{3}{|c|}{ Níveis de concentrado (\%) } & \multirow{2}{*}{$\mathrm{EP}^{1}$} \\
\hline & 35 & 50 & 65 & \\
\hline & \multicolumn{3}{|c|}{ Peso absoluto, $\mathrm{kg}$} & \\
\hline Cabeça & 13,03 & 12,92 & 13,00 & 0,34 \\
\hline Patas & 6,29 & 6,41 & 6,52 & 0,22 \\
\hline Vassoura da cauda & 0,18 & 0,14 & 0,18 & 0,04 \\
\hline Couro & 28,09 & 30,61 & 31,14 & 1,10 \\
\hline \multirow[t]{2}{*}{ Total componentes externos } & 47,60 & 50,09 & 50,82 & 1,40 \\
\hline & \multicolumn{3}{|c|}{$\%$ do corpo vazio } & \\
\hline Cabeça & $4,67 \mathrm{a}$ & $4,30 \mathrm{~b}$ & $4,28 \mathrm{~b}$ & 0,08 \\
\hline Patas & 2,25 & 2,13 & 2,15 & 0,05 \\
\hline Vassoura da cauda & 0,06 & 0,05 & 0,06 & 0,01 \\
\hline Couro & 10,11 & 10,22 & 10,34 & 0,28 \\
\hline \multirow[t]{2}{*}{ Total componentes externos } & 17,10 & 16,70 & 16,82 & 0,27 \\
\hline & \multicolumn{3}{|c|}{$\%$ do peso de abate } & \\
\hline Cabeça & $3,88 \mathrm{a}$ & $3,66 \mathrm{~b}$ & $3,63 \mathrm{~b}$ & 0,07 \\
\hline Patas & 1,87 & 1,81 & 1,82 & 0,04 \\
\hline Vassoura da cauda & 0,05 & 0,04 & 0,05 & 0,01 \\
\hline Couro & 8,39 & 8,66 & 8,79 & 0,26 \\
\hline Total componentes externos & 14,19 & 14,19 & 14,29 & 0,26 \\
\hline
\end{tabular}

$1=$ erro padrão

$\mathrm{a}, \mathrm{b}=$ médias seguidas por letras minúsculas na linha diferem estatisticamente entre si $(\mathrm{P}<0,05)$ pelo teste " $\mathrm{t}$ ".

Fonte: Elaboração dos autores.

Missio et al. (2009) verificaram diminuição linear no peso de cabeça ajustado para PCV com o aumento de concentrado na dieta, relacionando este resultado ao aumento de outros componentes corporais, como a gordura interna que apresentou correlação negativa e significativa com o peso da cabeça. No presente estudo, novilhos alimentados com 50 e $65 \%$ de concentrado na dieta apresentaram maior quantidade de gordura interna do que novilhos que receberam 35\% (Tabela 4), no entanto, não houve correlação significativa entre estas variáveis.

De acordo com Pacheco et al. (2005a), a comercialização de bovinos de corte entre produtor e frigorífico no Brasil é feita com base no peso de carcaça quente, ou como na região sul, por meio do peso vivo ao abate. Apesar dos componentes externos não fornecerem remuneração ao produtor rural, estes são importantes, pois representam em 
torno de $15 \%$ do peso vivo do animal, influenciando Por outro lado, para os frigoríficos, os componentes a eficiência alimentar, o rendimento de carcaça e, externos já participam como fonte de receita, consequentemente, a receita líquida do produtor. principalmente sendo comercializados para preparo de rações e para curtumes.

Tabela 4. Pesos absolutos, em percentagem do peso vivo e em percentagem do peso de abate para as características de gorduras inguinal, renal, toalete, ruminal, intestinal, do abomaso, coração e total de novilhos alimentados com diferentes proporções de concentrado na dieta.

\begin{tabular}{|c|c|c|c|c|}
\hline \multirow{2}{*}{ Gordura } & \multicolumn{3}{|c|}{ Níveis de concentrado (\%) } & \multirow{2}{*}{$\mathrm{EP}^{1}$} \\
\hline & 35 & 50 & 65 & \\
\hline \multicolumn{5}{|c|}{ Peso absoluto, $\mathrm{kg}$} \\
\hline Inguinal & 2,09 & 2,31 & 2,18 & 0,15 \\
\hline Renal & 2,07 & 2,50 & 2,14 & 0,16 \\
\hline Toalete & 4,28 & 4,61 & 4,52 & 0,26 \\
\hline Ruminal & 1,87 & 2,42 & 3,06 & 0,78 \\
\hline Intestinal & 6,40 & 7,96 & 7,63 & 0,60 \\
\hline Abomaso & $0,89 b$ & $2,07 \mathrm{a}$ & $1,53 \mathrm{ab}$ & 0,21 \\
\hline Coração & 0,53 & 0,70 & 0,67 & 0,09 \\
\hline Total & $18,13 b$ & $22,58 \mathrm{a}$ & $21,74 \mathrm{a}$ & 1,22 \\
\hline \multicolumn{5}{|c|}{$\%$ do corpo vazio } \\
\hline Inguinal & 0,76 & 0,77 & 0,72 & 0,05 \\
\hline Renal & 0,75 & 0,83 & 0,71 & 0,05 \\
\hline Toalete & 1,53 & 1,52 & 1,48 & 0,08 \\
\hline Ruminal & 0,66 & 0,80 & 1,00 & 0,26 \\
\hline Intestinal & 2,29 & 2,63 & 2,55 & 0,20 \\
\hline Abomaso & 0,32 & 0,68 & 0,50 & 0,07 \\
\hline Coração & 0,19 & 0,23 & 0,22 & 0,03 \\
\hline Total & 6,50 & 7,47 & 7,20 & 0,35 \\
\hline \multicolumn{5}{|c|}{$\%$ do peso de abate } \\
\hline Inguinal & 0,63 & 0,65 & 0,62 & 0,04 \\
\hline Renal & 0,62 & 0,70 & 0,60 & 0,04 \\
\hline Toalete & 1,27 & 1,29 & 1,25 & 0,06 \\
\hline Ruminal & 0,55 & 0,68 & 0,87 & 0,23 \\
\hline Intestinal & 1,90 & 2,24 & 2,16 & 0,17 \\
\hline Abomaso & $0,26 b$ & $0,58 \mathrm{a}$ & $0,42 \mathrm{ab}$ & 0,06 \\
\hline Coração & 0,16 & 0,20 & 0,19 & 0,03 \\
\hline Total & 5,39 & 6,35 & 6,13 & 0,32 \\
\hline
\end{tabular}

$1=$ erro padrão

$\mathrm{a}, \mathrm{b}=$ médias seguidas por letras minúsculas na linha diferem estatisticamente entre si $(\mathrm{P}<0,05)$ pelo teste " $\mathrm{t}$ ".

Fonte: Elaboração dos autores.

O peso total das gorduras depositadas nas vísceras foi maior $(\mathrm{P}<0,05)$ em novilhos alimentados com 50 e $65 \%$ de concentrado na dieta (Tabela 4), o que era esperado, uma vez que, estes animais consumiram mais energia. Este maior peso total das gorduras internas para os novilhos alimentados nas proporções de 50 e $65 \%$ de concentrado na dieta proporcionou maior PCV, já demonstrado na Tabela 2, para animais destes tratamentos, comprovada pela análise de correlação entre peso da gordura interna e PCV que foi positiva e significativa $(r=0,66 ; P=0,0008)$. No entanto, a diferença do peso 
total das gorduras depositadas nas vísceras quando expressa em relação ao PCV e ao PA, deixou de ser significativa $(\mathrm{P}>0,05)$. Jones, Rompala e Jeremiah (1985) alimentando novilhos com dieta concentrada e volumosa observaram acréscimo no depósito de gordura em novilhos alimentados com concentrado (17,6 e 12,9\%, respectivamente) em relação aos que consumiram dieta rica em volumoso, representando $36 \%$ de gordura a mais. Ribeiro et al. (2001) avaliando o tamanho relativo dos órgãos internos e vísceras de bezerros holandeses alimentados com 45, 60, 75 e 90\% de concentrado na dieta observaram que os bezerros alimentados com $90 \%$ de concentrado apresentaram maior proporção de gordura interna do que os alimentados com $45 \%$ de concentrado na dieta. De acordo com Owens et al. (1995), maiores quantidades de gordura interna, implica em aumento das exigências de mantença dos animais, devido a maior atividade metabólica do tecido adiposo. Além disso, a gordura interna não é aproveitada para consumo humano, acarretando em desperdício de energia alimentar e penalidade para o produtor, por ser eliminada da carcaça sem remuneração alguma (FERREIRA et al., 2000).

Novilhos Charolês $(\mathrm{CH})$ apresentaram peso absoluto da cabeça e patas superiores aos novilhos Nelore (NE). No entanto, não foi suficiente para alterar o total dos componentes externos (Tabela 5). Menezes et al. (2009) também encontraram superioridade para novilhos $\mathrm{CH}$ em relação aos NE para os pesos de cabeça, patas e vassoura da cauda. Da mesma forma, Fernandes et al. (2005) encontraram maior peso da cabeça para os novilhos 1/2 Caracu x 1/2 Nelore em comparação aos $1 / 2$ Holandês x 1/2 Nelore e Nelore puro.

Tabela 5. Médias e erros-padrão para características de cabeça, patas, vassoura da cauda, couro e o total dos componentes externos em peso absoluto, em percentagem do peso de corpo vazio e do peso de abate de novilhos Charolês e Nelore.

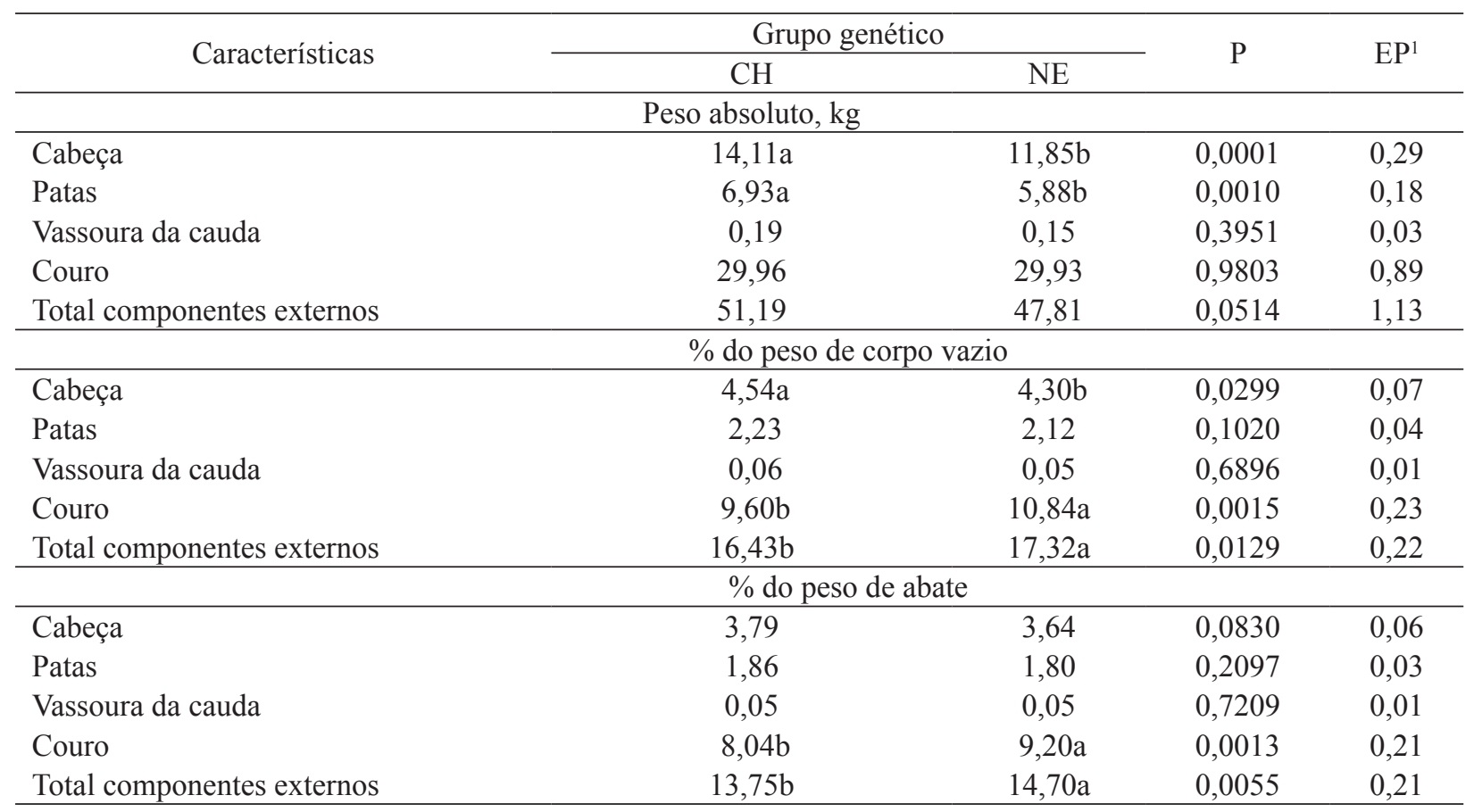

${ }^{1} \mathrm{EP}=$ erro padrão;

$\mathrm{a}, \mathrm{b}=$ médias seguidas por letras minúsculas na linha diferem estatisticamente entre si $(\mathrm{P}<0,05)$ pelo teste " $\mathrm{t}$ ".

Fonte: Elaboração dos autores. 
Quando expresso em relação à \% $\mathrm{PCV}$, os valores de couro foi superior $(\mathrm{P}<0,05)$ para os novilhos $\mathrm{NE}$ em relação aos $\mathrm{CH}(10,84$ vs 9,60 , respectivamente). Isto pode estar relacionado à maior superfície corporal dos NE, em razão de apresentar barbela e cupim mais desenvolvido (PACHECO et al., 2005a). O total dos componentes externos quando ajustado para PCV e PA foi maior para os novilhos $\mathrm{NE}(\mathrm{P}>0,05)$ do que os novilhos $\mathrm{CH}$, provavelmente em função do maior peso do couro apresentado pelos novilhos NE. Backes et al. (2006) avaliando o tamanho relativo dos órgãos internos e do trato gastrintestinal de bovinos zebu e mestiços leiteiros, na fase de recria, verificaram que os animais zebu apresentaram couro mais pesado do que os mestiços leiteiros, corroborando com os resultados deste trabalho. De maneira geral, os zebuínos têm apresentado maiores valores para o total dos componentes externos do que animais europeus e mestiços europeu-zebu (JORGE et al., 1999; PACHECO et al., 2005a; BACKES et al., 2006).

O peso da gordura de toalete (Tabela 6) foi maior $(\mathrm{P}<0,05)$ em novilhos $\mathrm{CH}$ do que em $\mathrm{NE}$, nas três formas de expressão. Esta superioridade influenciou o peso absoluto do total das gorduras descartadas, sendo mais elevado $(\mathrm{P}<0,05)$ em novilhos $\mathrm{CH}$. No entanto, quando ajustado para PCV e PA, esta diferença deixou de existir. Resultados deste estudo concordam com os encontrados por Menezes et al. (2009), nos quais avaliaram a distribuição de gorduras internas e de descarte no corpo de novilhos puros e cruzados das raças Charolês e Nelore terminados em confinamento. Por sua vez, Kuss et al. (2007) não encontraram diferença no total de gordura descartada de vacas mestiças Charolês/Nelore.
Restle et al. (2002) avaliaram as características quantitativas das carcaças de vacas de descarte das raças Charolês e Nelore e suas cruzas, e observaram que a deposição de gordura subcutânea foi $79 \%$ superior nos animais Nelore, apresentando valores médios de 4,59 vs 8,22 mm, para vacas $\mathrm{CH}$ e $\mathrm{NE}$, respectivamente. Perón et al. (1993), comparando as proporções de gordura interna e externa de animais abatidos com alimentação normal e restrita, observaram que a proporção de gordura interna foi maior nos animais abatidos com peso mais elevado, ocorrendo menor percentagem de gordura externa nesses animais. No presente estudo, os novilhos $\mathrm{CH}$ apresentaram maiores peso de abate e maior depósito de gordura interna, concordando com os resultados dos autores citados anteriormente. Com isso, o maior requerimento de energia de mantença para os taurinos é influenciado pelo maior acúmulo de gordura interna (BACKES et al., 2006).

$\mathrm{O}$ peso da gordura inguinal ajustada para PCV e PA foi diferente para as raças estudadas (Tabela 6). Maior acúmulo de gordura inguinal foi verificado nos novilhos NE em comparação aos $\mathrm{CH}$. Pacheco et al. (2005a), verificaram maiores peso de gordura inguinal em novilhos super jovens $5 / 8 \mathrm{CH} \times 3 / 8 \mathrm{NE}$ em relação aos 5/8NE x 3/8CH. Concordando com Perón et al (1993), menores valores dessa gordura são desejáveis, pois o aumento desta contribui para menores rendimentos de carcaça, e aumenta as exigências de manutenção dos animais. Segundo Leme et al. (2000) as gorduras renal, pélvica e inguinal expressas em $\mathrm{kg}$ ou em \% da carcaça, são o melhor indicador da gordura depositada no corpo. 
Tabela 6. Pesos absolutos, em percentagem do peso vivo e em percentagem do peso de abate para as gorduras inguinal, renal, toalete, ruminal, intestinal, abomasal, do coração e total de novilhos Charolês $(\mathrm{CH})$ e Nelore (NE).

\begin{tabular}{|c|c|c|c|c|}
\hline \multirow{2}{*}{ Gordura } & \multicolumn{2}{|c|}{ Grupo genético } & \multirow{2}{*}{$\mathrm{P}$} & \multirow{2}{*}{$\mathrm{EP}^{1}$} \\
\hline & $\mathrm{CH}$ & $\mathrm{NE}$ & & \\
\hline \multicolumn{5}{|c|}{ Peso absoluto, kg } \\
\hline Inguinal & 2,04 & 2,35 & 0,1070 & 0,13 \\
\hline Renal & 2,36 & 2,12 & 0,2393 & 0,14 \\
\hline Toalete & $5,19 \mathrm{a}$ & $3,74 \mathrm{~b}$ & 0,0002 & 0,22 \\
\hline Ruminal & 2,59 & 2,31 & 0,7573 & 0,64 \\
\hline Intestinal & 7,93 & 6,73 & 0,0963 & 0,49 \\
\hline Abomaso & 1,68 & 1,31 & 0,1540 & 0,18 \\
\hline Coração & 0,73 & 0,54 & 0,1000 & 0,07 \\
\hline Total & $22,52 \mathrm{a}$ & $19,11 \mathrm{~b}$ & 0,0256 & 0,98 \\
\hline \multicolumn{5}{|c|}{$\%$ do corpo vazio } \\
\hline Inguinal & $0,65 b$ & $0,85 \mathrm{a}$ & 0,0031 & 0,04 \\
\hline Renal & 0,75 & 0,77 & 0,8267 & 0,04 \\
\hline Toalete & $1,66 \mathrm{a}$ & $1,36 \mathrm{~b}$ & 0,0047 & 0,06 \\
\hline Ruminal & 0,84 & 0,81 & 0,9131 & 0,21 \\
\hline Intestinal & 2,55 & 2,43 & 0,6190 & 0,16 \\
\hline Abomaso & 0,53 & 0,47 & 0,4952 & 0,06 \\
\hline Coração & 0,23 & 0,19 & 0,2804 & 0,02 \\
\hline Total & 7,23 & 6,88 & 0,4148 & 0,29 \\
\hline \multicolumn{5}{|c|}{$\%$ peso de abate } \\
\hline Inguinal & $0,55 b$ & $0,72 \mathrm{a}$ & 0,0028 & 0,03 \\
\hline Renal & 0,63 & 0,65 & 0,7159 & 0,04 \\
\hline Toalete & $1,39 a$ & $1,15 b$ & 0,0071 & 0,05 \\
\hline Ruminal & 0,70 & 0,70 & 0,9886 & 0,19 \\
\hline Intestinal & 2,14 & 2,07 & 0,7244 & 0,14 \\
\hline Abomaso & 0,45 & 0,40 & 0,5349 & 0,05 \\
\hline Coração & 0,20 & 0,16 & 0,3105 & 0,02 \\
\hline Total & 6,05 & 5,86 & 0,6075 & 0,27 \\
\hline
\end{tabular}

${ }^{1} \mathrm{EP}=$ erro padrão;

$\mathrm{a}, \mathrm{b}=$ médias seguidas por letras minúsculas na linha diferem estatisticamente entre si $(\mathrm{P}<0,05)$ pelo teste " $\mathrm{t}$ ".

Fonte: Elaboração dos autores.

\section{Conclusões}

Novilhos Charolês depositam mais gordura na cavidade interna do corpo do que novilhos Nelore. Novilhos Nelore apresentam couro mais pesado do que novilhos Charolês. Proporções mais altas de concentrado na dieta permitem maiores depósitos de gordura interna no corpo de novilhos Charolês ou Nelore.

\section{Referências}

BACKeS, A. A.; PAUlinO, M. F.; ALVES, D. D.; RENNÓ, L. N.; VALADARES FILHO, S. C.; LANA, R. P. Tamanho relativo dos órgãos internos e do trato gastrintestinal de bovinos Zebu e mestiços leiteiros em sistema de recria. Ciência Rural, Santa Maria, v. 36, n. 2, p. 594-598, 2006.

DI MARCO, O. N. Crecimiento de vacunos para carne. Mar del Plata: Balcarce, 1998. 246 p. 
FATURI, C.; RESTLE, J.; BRONDANI, I. L.; SILVA, J. H. S.; ARBOITTE, M. Z.; CARRILHO, C. O.; PEIXOTO, L. A. O. Características da carcaça e da carne de novilhos de diferentes grupos genéticos alimentados em confinamento com diferentes proporções de grão de aveia e grão de sorgo no concentrado. Revista Brasileira de Zootecnia, Viçosa, MG, v. 31, n. 5, p. 2024-2035, 2002.

FERNANDES, H. J.; PAULINO, M. F.; MARTINS, R. G. R.; VALADARES FILHO, S. C.; TORRES, A. R.; PAIVA, L. M.; RIBEIRO, V. A. Crescimento de componentes corporais de três grupos genéticos na fases de recria e terminação. Revista Brasileira de Zootecnia, Viçosa, MG, v. 34, n. 1, p. 288-299, 2005.

FERREIRA, M. A.; VALADARES FILHO, S. C.; MUNIZ, E. B.; VÉRAS, A. S. C. Características das carcaças, biometria do trato gastrintestinal, tamanho dos órgãos internos e conteúdo gastrintestinal de bovinos F1 Simental x Nelore, alimentados com vários níveis de concentrados. Revista Brasileira de Zootecnia, Viçosa, MG, v. 29, n. 4, p. 1174-1182, 2000.

GAlvÃO, J. G.; FONTES, C. A. A.; PIRES, C. C.; CARNEIRO, L. H. D.; QUEIROZ, A. C.; PAULINO, M. F. Características e composição física da carcaça de bovinos não-castrados, abatidos em três estágios de maturidade de três grupos raciais. Revista Brasileira de Zootecnia, Viçosa, MG, v. 20, n. 5, p. 502-512, 1991.

GESUALDI JÚNIOR, A.; VELOSO, C. M.; PAULINO, M. F.; VALADARES FILHO, S. C.; GESUALDI, A. C. L.; CECON, P. R. Níveis de concentrado na dieta de bovinos $\mathrm{F}_{1}$ Limousin x Nelore: Peso dos órgãos internos e trato digestivo. Revista Brasileira de Zootecnia, Viçosa, MG, v. 30, n. 6, p. 1866-1871, 2001.

JONES, S. D. M.; ROMPALA, R. E.; JEREMIAH, L. E. Growth and composition of the empty body in steers of different maturity types fed concentrate or forage diets. Journal of Animal Science, Illinois, v. 60, n. 2, p. 427433, 1985.

JORGE, A. M.; FONTES, C. A. A.; PAULINO, M. F.; GOMES JÚNIOR, P. Tamanho relativo dos órgãos internos de zebuínos sob alimentação restrita e ad libitum. Revista Brasileira de Zootecnia, Viçosa, MG, v. 28, n. 2, p. 374-380, 1999.

KUSS, F.; BARCELLOS, J. O. J.; LÓPEZ, J.; RESTLE, J.; MOLETTA, J. L.; PAULA, M. C. Componentes nãointegrantes da carcaça de novilhos não-castrados ou castrados terminados em confinamento e abatidos aos 16 ou 26 meses de idade. Revista Brasileira de Zootecnia, Viçosa, MG, v. 37, n. 10, p. 1829-1836, 2008.
KUSS, F.; RESTLE, J.; BRONDANI, I. L.; PASCOAL, L. L; MENEZES, L. F. G.; LEITE, D. T.; SANTOS, M. F. Componentes externos do corpo e gordura de descarte em vacas mestiças Charolês x Nelore abatidas com diferentes pesos. Revista Brasileira de Zootecnia, Viçosa, MG, v. 36, n. 4, p. 865-873, 2007.

LEME, P. R.; BOIN, C.; MARGARIDO, R. C. C.; TEDESCHI, L. O.; HAUSKNECHT, J. C. O. V.; ALLEONI, G. F.; LUCHIARI FILHO, A. Desempenho em confinamento e características de carcaça de bovinos machos de diferentes cruzamentos abatidos em três faixas de peso. Revista Brasileira de Zootecnia, Viçosa, v. 29, n. 6, p. 2347-2353, 2000. Suplemento.

MENEZES, L. F. G.; RESTLE, J. Desempenho de novilhos de gerações avançadas do cruzamento alternado entre as raças Charolês e Nelore, terminados em confinamento. Revista Brasileira de Zootecnia, Viçosa, MG, v. 34, n. 6, p. 1927-1937, 2005.

MENEZES, L. F. G.; RESTLE, J.; BRONDANI, I. L.; ALVES FILHO, D. C.; PASCOAL, L. L.; SILVA, J. H. S. Distribuição de gorduras internas e de descarte e componentes externos do corpo de novilhos de gerações avançadas do cruzamento rotativo entre as raças Charolês e Nelore. Revista Brasileira de Zootecnia, Viçosa, v. 38, n. 2, p. 338-345, 2009.

MENEZES, L. F. G.; RESTLE, J.; BRONDANI, I. L.; ALVES FILHO, D. C.; KUSS, F.; SILVEIRA, M. F.; AMARAL, G. A. Características da carcaça de novilhos de gerações avançadas do cruzamento alternado entre as raças Charolês e Nelore, terminados em confinamento. Revista Brasileira de Zootecnia, Viçosa, MG, v. 34, n. 3, p. 934-945, 2005.

MISSIO, R. L.; BRONDANI, I. L.; RESTLE, J.; SILVA, J. H. S.; SILVEIRA, M. F.; SILVA, V. S. Partes não-integrantes da carcaça de tourinhos alimentados com diferentes níveis de concentrado na dieta. Revista Brasileira de Zootecnia, Viçosa, MG, v. 38, n. 5, p. 906915, 2009.

OWENS, F. N.; GILL, D. R.; SECRIST, D. S.; COLEMAN, S. W. Review of some aspects of growth and development of feedlot cattle. Journal of Animal Science, Illinois, v. 73, n. 10, p. 3152-3172, 1995.

PACHECO, P. S.; RESTLE, J.; SILVA, J. H. S.; ARBOITTE, M. Z.; ALVES FILHO, D. C.; FREITAS, A. K.; ROSA, J. R. P.; PÁDUA, J. T. Características das partes do corpo não-integrantes da carcaça de novilhos jovens e superjovens de diferentes grupos genéticos. Revista Brasileira de Zootecnia, Viçosa, MG, v. 34, n. 5, p. 1678-1690, 2005a. 
PACHECO, P. S.; SILVA, J. H. S.; RESTLE, J.; ARBOITTE, M. Z.; BRONDANI, I. L.; ALVES FILHO, D. C.; FREITAS, A. K. Características quantitativas da carcaça de novilhos jovens e superjovens de diferentes grupos genéticos. Revista Brasileira de Zootecnia, Viçosa, MG, v. 34, n. 5, p. 1666-1677, 2005 b.

PERÓN, A. J.; FONTES, C. A. A.; LANA, R. P.; SILVA, D. J.; QUEIROZ, A. C.; PAULINO, M. F. Tamanho de órgãos internos e distribuição da gordura corporal em novilhos de cinco grupos genéticos, submetidos à alimentação restrita e ad libitum. Revista Brasileira de Zootecnia, Viçosa, MG, v. 22, n. 5, p. 813-819, 1993.

RESTLE, J.; PASCOAL, L. L.; FATURI, C.; ALVES FILHO, D. C.; BRONDANI, I. L.; PACHECO, P. S.; PEIXOTO, L. A. O. Efeito do grupo genético e da heterose nas características quantitativas da carcaça de vacas de descarte terminadas em confinamento. Revista Brasileira de Zootecnia, Viçosa, MG, v. 31, n. 1, p. 350362, 2002. Suplemento.

RESTLE, J.; VAZ, F. N.; FEIJÓ, G. L. D.; BRONDANI, I. L.; ALVES FILHO, D. C.; BERNARDES, R. A. C.; FATURI, C.; PACHECO, P. S. Características de carcaça de bovinos inteiros ou castrados de diferentes composições raciais Charolês $\mathrm{x}$ Nelore. Revista Brasileira de Zootecnia, Viçosa, MG, v. 29, n. 5, p. 13711379, 2000.

RESTLE, J.; VAZ, F. N.; ROSO, C.; OLIVEIRA, A. N.; CERDÓTES, L.; MENEZES, L. F. G. Desempenho e características da carcaça de vacas de diferentes grupos genéticos em pastagem cultivada com suplementação energética. Revista Brasileira de Zootecnia, Viçosa, MG, v. 30, n. 6, p. 1813-1823, 2001.
RIBEIRO, T. R.; PEREIRA, J. C.; LEÃO, M. I.; OLIVEIRA, M. V. M.; QUEIROZ, A. C.; CECON, P. R.; MELO, R. C. A. Tamanho de órgãos e vísceras de bezerros holandeses, para a produção de vitelos, recebendo dietas com diferentes níveis de concentrado. Revista Brasileira de Zootecnia, Viçosa, MG, v. 30, n. 6, p. 2163-2168, 2001.

STATISTICAL ANALYSIS SYSTEM INSTITUTE SAS. Institute Incorporation. SAS Language Reference. Version 6. Cary, NC: SAS institute, 2001. 1042 p.

THOMPSON, W. R.; MEISKE, J. C.; GOODRICH, R. D.; RUST, J. R.; BYERS, F. M. Influence of body composition on energy requirement of breed cows during winter. Journal of Animal Science, Illinois, v. 56, n. 5, p. 1241-1251, 1983.

VAN SOEST, P. J. Nutritional ecology of the ruminant. 2. ed. Ithaca: Cornell University Press, 1994. 476 p.

VELOSO, C. M.; VALADARES FILHO, S. C.; GESUALDI JÚNIOR, A.; SILVA, F. F.; PAULINO, M. F.; VALADARES, R. F. D.; CECON, P. R.; PAULINO, P. V. R. Composição corporal e exigências energéticas e protéicas de bovinos F1 Limousin x Nelore, nãocastrados, alimentados com rações contendo diferentes níveis de concentrado. Revista Brasileira de Zootecnia, Viçosa, MG, v. 31, n. 3, p. 1273-1285, 2002. 
